\title{
Accelerator Mass Spectrometry
}

National Cancer Institute

\section{Source}

National Cancer Institute. Accelerator Mass Spectrometry. NCI Thesaurus. Code C135452.

A type of mass spectrometry in which ions in the sample are accelerated to very high kinetic energies, thus allowing for the separation of rare isotopes from more abundant isotopes. 